\title{
INTEGRAÇÃO LAVOURA-PECUÁRIA: EFICIÊNCIA DE USO DO NITROGENIO NA CULTURA DO MILHO
}

\section{CROP-LIVESTOCK INTEGRATION: USE EFFICIENCY OF NITROGEN IN CORN CULTURE}

\author{
Claudete Reisdorfer LANG ${ }^{(1)}$ \\ Adelino PELISSARI ${ }^{(1)}$ \\ Anibal de MORAES ${ }^{(1)}$ \\ Reuben Mark SULC ${ }^{(2)}$ \\ Paulo César de Faccio CARVALHO(3) \\ Édina Cristiane Pereira LOPES ${ }^{(4)}$
}

\begin{abstract}
RESUMO
O aumento da eficiência de produção para a cultura do milho (Zea mays) tem levado os produtores a buscarem alternativas sustentáveis através de sistemas integrados. O objetivo deste trabalho foi determinar o efeito do nitrogênio na produtividade do milho e seus componentes de rendimento, em um sistema de integração lavoura-pecuária. O experimento foi conduzido na fazenda experimental Capão da Onça da Universidade Estadual de Ponta Grossa, Brasil, durante a safra agrícola de 2002/2003. O delineamento experimental foi de blocos completos casualizados com parcelas subdivididas e quatro repetições. Os tratamentos foram duas doses de $N\left(0\right.$ e $\left.150 \mathrm{~kg} \mathrm{ha}^{-1}\right) \mathrm{com}$ e sem pastejo aplicados no inverno sobre aveia preta mais azevém estabelecidas em abril de 2002 e dessecadas para o plantio do milho em outubro do mesmo ano. Sequencialmente, os tratamentos aplicados no milho foram doses de $\mathrm{N}\left(0,75,150,225 \mathrm{~kg} \mathrm{ha}^{-1}\right)$. O milho apresentou uma resposta de produtividade crescente para o aumento das doses de nitrogênio nas áreas sem pastejo e sem adubação nitrogenada no inverno, no entanto quando há o pastejo é possível alcançar maiores produtividades de milho com menores doses de nitrogênio.
\end{abstract}

Palavras-chave: adubação nitrogenada; Avena strigosa Schreb; Lolium multiflorum L.; pastejo.

\section{ABSTRACT}

Producers seeking higher corn (Zea mays) production efficiency have pursued more sustainable, integrated systems. The objective of this investigation was to determine the effect of nitrogen fertilization on corn yield and yield components in an integrated crop-livestock production system. The experiment was conducted on the experimental farm Fazenda Capão da Onça of the Universidade Estadual de Ponta Grossa, Brazil during the 2002/2003 harvest. Treatments were replicated four times in a split-plot randomization of a randomized complete block design. Whole plot treatments were two $\mathrm{N}$ rates $\left(0,150 \mathrm{~kg} \mathrm{ha}^{-1}\right)$ with and without grazing applied to a winter cover crop of black oat and Italian ryegrass established in April 2002 and desiccated prior to planting the corn in October 2002. Sequentially, treatments were four $\mathrm{N}$ rates $\left(0,75,150,225 \mathrm{~kg} \mathrm{ha}^{-1}\right)$ applied to the corn. The corn presented an increasing yield in relation to increasing $\mathrm{N}$ rates in plots without neither grazing nor $\mathrm{N}$ fertilization during winter; however, grazing allows for higher corn yields with lower $\mathrm{N}$ rates.

Key-words: nitrogen fertilization; Avena strigosa Schreb; Lolium multiflorum L.; grazing.

\footnotetext{
1 Professor Adjunto do Departamento de Fitotecnia e Fitossanitarismo da Universidade Federal do Paraná (UFPR). Rua dos Funcionários, 1540, Curitiba - PR. CEP 80035-050. Caixa Postal 19061. E-mail: langc@ufpr.br, linopeli@hotmail.com, anibalm@ufpr.br.

2 Professor Adjunto da The Ohio State University. E-mail: sulc.2@osu.edu

${ }^{3}$ Professor do Departamento de Plantas Forrageiras e Agrometeorologia da UFRGS. End. Av. Bento Gonçalves 7712, Porto Alegre - RS. CEP 91501-970. E-mail: paulocfc@ufrgs.br

${ }^{4}$ Doutoranda do Programa de Pós-Graduação em Agronomia - Produção Vegetal da UFPR. End. Rua dos Funcionários, 1540, Curitiba - PR. CEP 80035-050. E-mail: edina.agronomia@gmail.com
} 


\section{INTRODUÇÃO}

$A$ adubação nitrogenada $(N)$ é considerada um dos principais fatores limitantes da produção de milho, interferindo diretamente nos componentes de rendimento da cultura (Amado et al., 2002). Vários fatores ambientais interferem nessa eficência de mineralização do nitrogênio orgânico e provavelmente o teor de matéria orgânica seja a que melhor representa a qualidade deste solo e disponibilidade de N (Mello et al., 1989), podendo ser alcançada pela utilização de culturas que produzam uma alta adição de biomassa, em sistema de plantio direto, com integração lavourapecuária.

A quantidade de nitrogênio existente no solo, na maioria dos sistemas de produção do Sul do Brasil não é suficiente para satisfazer a demanda total deste nutriente para as culturas (Spera et al., 2009). Por isso a utilização de sistemas integrando lavoura e pecuária, asseguram a sustentabilidade do sistema produtivo (Baethgen, 1992).

O nitrogênio é um dos elementos mais abundantes na natureza, seus constituintes essenciais são os ácidos nucléicos e as proteínas (Taiz e Zeiger, 2009) e é necessário que todos os nutrientes estejam disponíveis em quantidades (concentrações) suficientes para que suas exigências nutricionais sejam atendidas (Cantarella e Duarte, 2004).

O pastejo pode influenciar os processos de mineralização e imobilização de $\mathrm{N}$, facilitando a rápida decomposição de substratos (Singh et al., 1991), e aumentar a taxa de reciclagem de $\mathrm{N}$ resultante da deposição de urina e fezes (Bayer e Mielniczuck, 1997).

Pode-se afirmar que o pastejo, altera as propriedades químicas do solo e consequentemente as propriedades físicas e biológicas, devido ao sinergismo existente entre elas, ocasionando algumas vezes redução de produtividade, por meio da compactação proporcionada pelo pisoteio do animal, tendo como conseqüência o aumento da resistência mecânica à penetração radicular, redução da aeração, umidade e disponibilidade de nutrientes (Assmann et al., 2003). Entretanto, cabe ressaltar que a área efetivamente pisoteada depende do comportamento do animal em resposta ao clima, disponibilidade de forragem, estado fisiológico e demanda nutricional (Watkins e Clements, 1978).

Neste sentido, o objetivo deste trabalho foi avaliar o efeito da adubação nitrogenada e pastejo na cobertura de inverno, sobre os componentes de rendimento e a produtividade do milho submetido a diferentes doses de nitrogênio em um sistema de integração lavoura-pecuária.

\section{MATERIAL E MÉTODOS}

A área experimental está localizada na região fisiográfica denominada de Segundo Planalto Paranaense, situada entre as coordenadas $25^{\circ} 05^{\prime} 47^{\prime \prime}$ de latitude Sul e $50^{\circ} 03^{\prime} 11^{\prime \prime}$ de longitude Oeste, com altitude média de 1025 m (IAPAR,
1994). O clima regional é classificado como Cfb subtropical mesotérmico úmido, de acordo com a classificação de Köppen. $\mathrm{O}$ solo da área experimental caracteriza-se como um Argissolo (Embrapa,1999), localizado na Fazenda Capão da Onça, pertencente à Universidade Estadual de Ponta Grossa.

A área experimental vinha sendo utilizada no sistema de plantio direto há cinco anos, seguindo uma rotação de cultivos utilizando as culturas da aveia branca (Avena strigosa), trigo (Triticum aestivum) e azevém (Lolium multiflorum) + aveia preta (Avena sativa) no inverno e milho (Zea mays), soja (Glycine max) e feijão (Phaseolus vulgarus) no verão.

Área total do experimento totalizou 6880 $\mathrm{m}^{2}$. Por ocasião da entrada dos animais, foram isoladas 8 parcelas denominadas área sem pastejo (SP), das quais a metade não recebeu nitrogênio $(\mathrm{N})$.

A área inicialmente de acesso ao pastejo dos animais media $7701 \mathrm{~m}^{2}$, para que permitisse a presença de um grupo de animais em pastejo contínuo ao longo do período experimental. As áreas não pastejadas e áreas diferidas foram isoladas dos animais por cerca elétrica.

A semeadura da mistura azevém + aveia preta foi realizado em plantio direto, no dia 10 de abril de 2002, utilizando-se $40 \mathrm{~kg} \mathrm{ha}^{-1}$ da mistura das sementes de ambas espécies $(60 \%$ de aveiapreta e $40 \%$ de azevém).

Nas parcelas com N, a adubação nitrogenada de cobertura foi realizada no dia $28 / 05 / 2002$, utilizando-se uréia como fonte de $N$, numa dosagem equivalente a $75 \mathrm{~kg} \mathrm{ha}^{-1}$ de $\mathrm{N}$ no início do perfilhamento e a segunda aplicação 39 dias após (em 06/07/2002), na dosagem de $75 \mathrm{~kg}$ $\mathrm{ha}^{-1}$ de $\mathrm{N}$, totalizando $150 \mathrm{~kg} \mathrm{ha}^{-1}$ de nitrogênio, somente aplicação nas parcelas com nitrogênio $(\mathrm{CN})$.

No dia $12 / 06 / 2002$ os animais foram pesados, após jejum de aproximadamente 16 horas. A entrada dos animais na área ocorreu neste mesmo dia, quando a pastagem apresentava um acúmulo aproximado de $1650 \mathrm{~kg} \mathrm{ha}^{-1}$ de massa seca. Foram utilizadas novilhas da raça Holandesa Preta e Branca, apresentando um peso médio de $292,5 \mathrm{~kg}$. O método de pastejo foi o contínuo utilizando-se 2 animais "testers" e um número variável de animais reguladores, que foram ajustados procurando-se manter uma massa de forragem próxima de $2 \mathrm{t}$ de $\mathrm{MS} \mathrm{ha}^{-1}$.

O delineamento experimental foi $\mathrm{o}$ de blocos ao acaso com parcelas subdivididas.

Para os procedimentos de estruturação e avaliação dos resultados, a análise estatística foi realizada considerando a pesquisa como composta por duas fases, a Fase I referente à cultura de inverno, e, a Fase II, à cultura de verão.

A Fase I correspondeu à pastagem de inverno, com os tratamentos com pastejo e sem pastejo, ambos com e sem nitrogênio e as diferentes intensidades de pastejo, definidas pelas 
LANG, C.R. et al., Integração lavoura pecuária ...

datas de retirada dos animais $(45,30,15$ e 0 dias antes da dessecação). A área submetida ao pastejo, que inicialmente media $7701 \mathrm{~m}^{2}$, aos 45 dias passou a medir $6741 \mathrm{~m}^{2}$, aos 30 dias ficou com uma área de $5781 \mathrm{~m}^{2}$, e aos 15 dias antes da dessecação a área pastejada ficou limitada em $4821 \mathrm{~m}^{2}$.

As sub-parcelas foram estabelecidas na Fase II é referente à cultura do milho, medindo $12 \mathrm{~m}$ x $5 \mathrm{~m}\left(60 \mathrm{~m}^{2}\right)$ cada, correspondendo as doses de nitrogênio $0,75,150$ e $225 \mathrm{~kg} \mathrm{ha}^{-1}$ aplicadas na cultura do milho, sendo nos tratamentos com e sem pastejo da Fase I.

No dia 31/10/2002 procedeu-se a semeadura do milho implantada no sistema de semeadura direta, utilizando-se sementes do Híbrido DK 215. Para isso, foram utilizadas 6 sementes por metro linear, em espaçamento de 80 $\mathrm{cm}$ entre linhas, devendo totalizar uma população aproximada de 70 mil plantas ha-1 ${ }^{-1}$ Como adubação de base, utilizou-se $300 \mathrm{~kg} \mathrm{ha}^{-1}$ da formulação 0-2020 (NPK) e $70 \mathrm{~kg} \mathrm{ha}^{-1}$ de $\mathrm{N}$, na forma de uréia, conforme análise do solo.

Quando o milho se encontrava no estádio V4, no dia 03/12 foi realizada a adubação complementar dos tratamentos, até completar as doses de nitrogênio de $75 \mathrm{~kg} \mathrm{ha}^{-1}, 150 \mathrm{~kg} \mathrm{ha}^{-1}$ e 225 $\mathrm{kg} \mathrm{ha}^{-1}$ de N.

Durante o ciclo da cultura o controle fitossanitário foi realizado segundo recomendações técnicas para a cultura e critérios adotados pelos produtores da região, realizando-se no dia 04/11/2002 uma aplicação de Sulfosate (960 g i.a. $\left.\mathrm{ha}^{-1}\right)+\left(\right.$ Atrazine $\left(1000 \mathrm{~g}\right.$ i.a. ha $\left.^{-1}\right)+$ Metalachlor $\left(550\right.$ g i.a. ha $\left.{ }^{-1}\right)+$ Clorpirifós $\left(860 \mathrm{~g} \mathrm{ha}^{-1}\right)$.

Para análises de teor de $\mathrm{N}$ nos tecidos das plantas de milho, foram coletadas amostras em uma área de $0,50 \mathrm{~m}^{2}$, nas bordaduras das duas linhas centrais, nos dias 18/11/2002, 08/12/2002 e 27/12/2002, períodos correspondentes aos estádios fisiológicos indicados por Jones Jr. et al. (1991). As plantas eram cortadas rente ao solo, e conduzidas para secagem em estufa de ar forçado a $60^{\circ} \mathrm{C}$ até peso constante. Após a secagem, as amostras foram moídas em moinho tipo "Willey" com peneira de $1 \mathrm{~mm}$. As análises do teor de $\mathrm{N}$ nos tecidos foram realizadas no Laboratório de Nutrição Animal do IAPAR (Instituto Agronômico do Paraná), conforme metodologia apropriada. Os valores dos teores do nitrogênio foram associados à quantidade de fitomassa aérea $\mathrm{ha}^{-1}$ das amostras e comparados à um modelo de diluição de nitrogênio descrito por Lemaire e Gastal (1997).

Para a avaliação dos componentes de rendimento da cultura do milho, fez-se a contagem do número de plantas nas duas linhas centrais $(6 \mathrm{~m}$ linear), e destas foram coletadas 10 plantas inteiras e de forma aleatória, das quais avaliou-se o número de grãos/espiga e massa de mil grãos. A produtividade de grãos foi estimada em $\mathrm{kg} \mathrm{ha}^{-1}$ do material coletado das duas linhas centrais e somados a massa de grãos avaliadas das 10 plantas coletadas para as medidas dos componentes de rendimento, após a realização da correção de umidade dos grãos para 13\%.

Para a análise das variáveis produtividade e componentes do rendimento utilizou-se o Programa Estatístico SANEST (Zonta et al., 1984). Para as análises da qualidade da fitomassa aérea residual e sua composição estrutural (porcentagens de folhas, colmos e material morto) utilizou-se o Programa STATIGRAPHICS

Os resultados das avaliações foram submetidas a análise de variância. As variáveis foram avaliadas pelo Teste de Bartlett quanto a homogeneidade. As que se mostraram homogêneas tiveram os tratamentos avaliados pelo Teste F. Quando os resultados revelaram significância ao nível de 5 ou $1 \%$ de probabilidade as médias dos fatores qualitativos (pastejo e nitrogênio) foram comparadas pelo Teste de Duncan ao nível de $5 \%$. Para os fatores quantitativos (doses de nitrogênio no verão) foram ajustadas regressões polinomiais.

\section{RESULTADOS E DISCUSSÃO}

Foram identificadas diferenças significativas quanto ao efeito das doses de nitrogênio aplicadas na cultura do milho para a variável número de grãos/espiga, sendo estes resultados semelhantes aos obtidos por Fernandes et al. (2005)

Nos tratamentos com e sem pastejo e com $\mathrm{N}$ no inverno, não se observou diferenças significativas quanto ao número de grãos/espiga nas doses de $\mathrm{N}$ aplicadas na cultura do milho (Tabela 1), assemelhando-se aos resultados obtidos por Balbinot Junior et al. (2009).

Para os tratamentos sem $\mathrm{N}$ no inverno (SPSN, CPSN) e nas intensidades de 15 e 30 dias de diferimento (CPCN 15, CPCN 30) o número de grãos/espiga foi menor na condição do milho não adubado com $\mathrm{N}$. No entanto, a produtividade do milho nestes tratamentos foi semelhante para todas as doses de $\mathrm{N}$ aplicadas na cultura do milho (Tabela 2). Para a intensidade de pastejo 45 (CPCN 45), não foi observado diferenças para o número de grãos/espiga (Tabela 1), porém neste tratamento, a produtividade de grãos na dosagem de $225 \mathrm{~kg} \mathrm{ha}^{-1}$ de $\mathrm{N}$ na cultura do milho foi inferior, não diferindo apenas dos tratamentos CPCN 15 e SPCN (Tabela 2). 
LANG, C.R. et al., Integração lavoura pecuária ...

TABELA 1. Número médio de grãos por espiga, em relação aos tratamentos aplicados sobre a pastagem e as doses de nitrogênio aplicados na cultura do milho, Fazenda "Capão da Onça", Ponta Grossa, PR, 2003.

\begin{tabular}{|c|c|c|c|c|}
\hline \multirow{3}{*}{$\begin{array}{c}\text { Tratamentos sobre } \\
\text { a pastagem de inverno }\end{array}$} & \multicolumn{4}{|c|}{ Doses de N no milho $\left(\mathrm{kg} \cdot \mathrm{ha}^{-1}\right)$} \\
\hline & 0 & 75 & 150 & 225 \\
\hline & \multicolumn{4}{|c|}{ 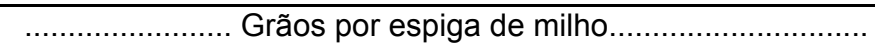 } \\
\hline $\mathrm{CPCN}$ & $372^{\mathrm{a}}$ & $448^{a}$ & $506^{\mathrm{a}}$ & $482^{\mathrm{a}}$ \\
\hline CPCN 15 & $347^{b}$ & $476^{\mathrm{ab}}$ & $493^{a}$ & $512^{\mathrm{a}}$ \\
\hline CPCN 30 & $352^{\mathrm{b}}$ & $450^{\mathrm{ab}}$ & $507^{a}$ & $501^{2}$ \\
\hline CPCN 45 & $438^{a}$ & $458^{a}$ & $520^{a}$ & $435^{\mathrm{a}}$ \\
\hline CPSN & $217^{b}$ & $464^{\mathrm{a}}$ & $488^{a}$ & $511^{\mathrm{a}}$ \\
\hline SPCN & $429^{a}$ & $476^{a}$ & $402^{a}$ & $412^{a}$ \\
\hline SPSN & $297^{b}$ & $441^{\mathrm{a}}$ & $482^{a}$ & $492^{a}$ \\
\hline
\end{tabular}

$\mathrm{CV}=9,71 \%$ para tratamentos e $\mathrm{CV}=15,6 \%$ para doses de $\mathrm{N}$. Médias seguidas da mesma letra não diferem na linha, pelo Teste de Duncan ao nível de $5 \%$ de probabilidade de erro. (Com pastejo com nitrogênio com retirada dos animais 15 dias antes da dessecação - CPCN15; Com pastejo com nitrogênio com retirada dos animais 30 dias antes da dessecação - CPCN30; Com pastejo com nitrogênio com retirada dos animais 45 dias antes da dessecação - CPCN45; Sem pastejo sem nitrogênio - SPSN; Sem pastejo com nitrogênio - SPCN; Com pastejo sem nitrogênio - CPSN; Com pastejo com nitrogênio - CPCN).

TABELA 2. Produtividade do milho obtida dos tratamentos aplicados sobre a pastagem de inverno, e diferentes doses de nitrogênio sobre a cultura do milho, Fazenda "Capão da Onça”, Ponta Grossa, PR, 2003.

\begin{tabular}{|c|c|c|c|c|}
\hline \multirow{3}{*}{$\begin{array}{c}\text { Tratamentos sobre } \\
\text { a pastagem de inverno }\end{array}$} & \multicolumn{4}{|c|}{ Doses de $\mathrm{N}$ no milho $\left(\mathrm{kg} \cdot \mathrm{ha}^{-1}\right)$} \\
\hline & 0 & 75 & 150 & 225 \\
\hline & \multicolumn{4}{|c|}{ 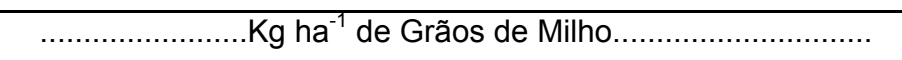 } \\
\hline $\mathrm{CPCN}$ & $5460^{\mathrm{bc}}$ & $8460^{\mathrm{ab}}$ & $9289^{\mathrm{ab}}$ & $9740^{\text {ab }}$ \\
\hline CPCN 15 & $5794^{\mathrm{b}}$ & $8218^{a b}$ & $8279^{\mathrm{ab}}$ & $9223^{a b c}$ \\
\hline CPCN 30 & $5107^{\mathrm{bc}}$ & $9358^{\mathrm{a}}$ & $8339^{\mathrm{ab}}$ & $9738^{\mathrm{ab}}$ \\
\hline CPCN 45 & $7515^{\mathrm{a}}$ & $8931^{\mathrm{ab}}$ & $9637^{a}$ & $8159^{c}$ \\
\hline CPSN & $2872^{d}$ & $8008^{a b}$ & $9256^{\mathrm{ab}}$ & $9739^{a b}$ \\
\hline SPCN & $7567^{\mathrm{a}}$ & $9255^{\mathrm{ab}}$ & $7813^{b}$ & $8063^{c}$ \\
\hline SPSN & $4127^{c d}$ & $7785^{\mathrm{b}}$ & $9352^{\mathrm{ab}}$ & $10288^{a}$ \\
\hline
\end{tabular}

Médias seguidas da mesma letra na linha, não diferem entre si pelo teste de Duncan à $5 \%$ de probabilidade de erro. (Com pastejo com nitrogênio - CPCN; Com pastejo com nitrogênio com retirada dos animais 15 dias antes da dessecação - CPCN15; Com pastejo com nitrogênio com retirada dos animais 30 dias antes da dessecação - CPCN30; Com pastejo com nitrogênio com retirada dos animais 45 dias antes da dessecação CPCN45; Com pastejo sem nitrogênio - CPSN; Sem pastejo com nitrogênio - SPCN; Sem pastejo sem nitrogênio - SPSN).

Pode-se observar na produtividade do milho, onde para a dose de $150 \mathrm{~kg} \mathrm{ha}^{-1}$ de $\mathrm{N}$ no tratamento CPSN, o milho produziu $9256 \mathrm{~kg} \mathrm{ha}^{-1}$ (Tabela 2), indicando respostas de aumento da produtividade do milho sobre adubação nitrogenada de $150 \mathrm{~kg} \mathrm{ha}^{-1}$.

Verifica-se no Tabela 2 que as maiores produções de milho, quando este não recebeu $\mathrm{N}$, ocorreram nos tratamentos CPCN 45 e SPCN diferindo dos demais. O tratamento CPSN resultou na mais baixa produção do milho $(2872 \mathrm{~kg}$ de grãos $\mathrm{ha}^{-1}$ ), não diferindo apenas do tratamento SPSN com $4127 \mathrm{~kg}$ de grãos $\mathrm{ha}^{-1}$, mostrando que a presença do animal não alterou a produtividade do milho e, sim, a não realização da adubação nitrogenada.

Dentro da dose de $75 \mathrm{~kg} \mathrm{ha}^{-1}$ de $\mathrm{N}$, apenas o tratamento SPSN diferenciou-se do CPCN 30 não diferindo dos demais que foram estatisticamente iguais entre si. Dentro da dose de $150 \mathrm{~kg} \mathrm{ha}^{-1}$ de N, o tratamento SPCN diferenciou-se do CPCN 45, não diferindo dos demais. $\mathrm{E}$, finalmente, dentro do nível de $225 \mathrm{~kg} \mathrm{ha}^{-1}$ houve uma maior produção do tratamento SPSN, diferindo apenas dos tratamentos CPCN 45 e SPCN, sendo que estes não diferiram entre si. As maiores diferenças entre os tratamentos aplicados na pastagem de inverno ocorreram na condição do milho sem adubação nitrogenada onde a resposta ao $\mathrm{N}$ residual aplicado na pastagem chegou a significar um aumento de $263 \%$ em 
relação ao tratamento CPSN (Tabela 2).

Nesta condição de manejo da pastagem de inverno o tratamento SPSN apresentou maior produtividade do que o tratamento CPSN, no entanto, o tratamento $\mathrm{CPCN}$ mostrou uma produtividade inferior ao tratamento SPCN.
O rendimento de grãos variou de $2872 \mathrm{~kg}$ ha $^{-1}$, para o tratamento que não recebeu adubação nitrogenada tanto no inverno como no verão, sofrendo pastejo (CPSN), até produtividade de $10288 \mathrm{~kg} \mathrm{ha}^{-1}$ para o tratamento SPSN (Figura 1).

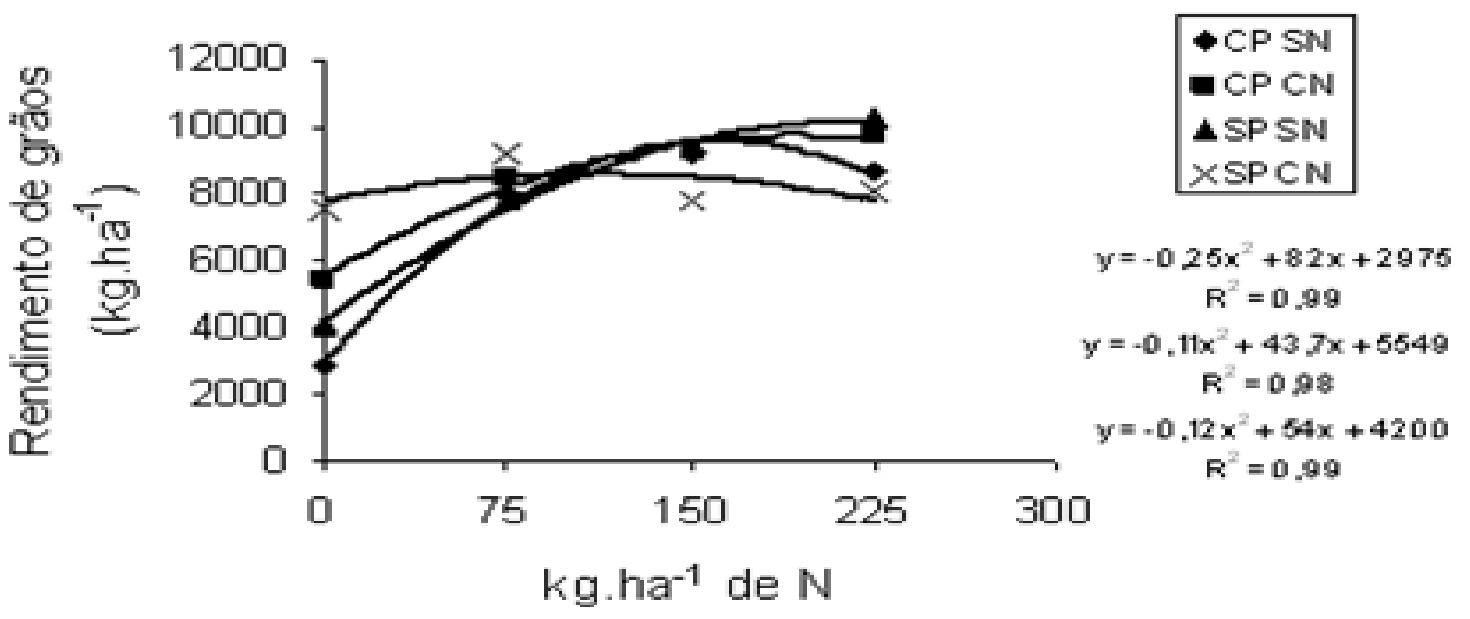

Figura 1. Rendimento de grãos de milho $\left(\mathrm{kg} \mathrm{ha}^{-1}\right)$ em resposta as doses de adubação nitrogenada na cultura do milho e pastagem de inverno com e sem nitrogênio, com e sem pastejo, Ponta Grossa, PR, 2003. (Com pastejo sem nitrogênio - CPSN; Com pastejo com nitrogênio - CPCN; Sem pastejo sem nitrogênio SPSN; Sem pastejo com nitrogênio - SPCN).

A contribuição do nitrogênio residual da pastagem para a cultura do milho pode ser comprovada pela produtividade obtida nas áreas com pastejo que foram adubadas com N (CPCN) sem que o milho tenha recebido adubação nitrogenada (Tabela 2).

Para cada $\mathrm{kg}$ de $\mathrm{N}$ aplicado na pastagem, houve um aumento de produtividade do milho em $36,4 \mathrm{~kg} \mathrm{ha}^{-1}$. Apesar da existência de perdas por volatilização, lixiviação e a própria imobilização provocada pelo aumento da atividade microbiana pela presença dos excrementos dos animais (Luo et al., 2000), não houve um comprometimento da disponibilidade do nitrogênio para a cultura do milho. Isto pode ser comprovado pela curva de diluição do N (Lemaire e Gastal, 1997) apresentada na Figura 2, identificando que no início do desenvolvimento da cultura do milho havia um teor de $\mathrm{N}$ abaixo do crítico (teor de $\mathrm{N}$ mínimo para uma resposta adequada da produtividade da planta).

É possível que nesta fase tenha havido uma imobilização do $\mathrm{N}$ nos dias seguintes à dessecação da pastagem de inverno. A aplicação do $\mathrm{N}$ na cultura do milho elevou os teores para valores considerados adequados pelo modelo. Passada esta fase inicial verifica-se sobre o modelo que a exceção dos tratamentos sem $\mathrm{N}$ todos os demais que receberam $\mathrm{N}$, seja na pastagem de inverno como na cultura do milho, permitiram às plantas manter um teor de $\mathrm{N}$ acima do ponto crítico.

Quando se analisa o potencial de produção de grãos pela quantidade de nitrogênio aplicado na pastagem (150 kg ha $\left.{ }^{-1}\right)$, sem pastejo (SPCN) e zero de nitrogênio no milho, se obtém um rendimento de $7568 \mathrm{~kg} \mathrm{ha}^{-1}$ (Figura 1), bem superior a média do Estado do Paraná que no ano de 1999, foi de 3432 $\mathrm{kg} \mathrm{ha}^{-1}$ (Gerage, 2000).

As áreas que foram pastejadas $e$ adubadas no inverno (CPCN) mostraram resposta positiva para o aumento de produtividade do milho até dose de $225 \mathrm{~kg} \mathrm{ha}^{-1}$ de nitrogênio quando comparadas com as áreas SPCN (Figura 3), mostrando um aumento de produtividade até aplicação de $75 \mathrm{~kg} \mathrm{ha}^{-1}$ de $\mathrm{N}$, provavelmente isso se deve a maior biodiversidade microbiana do solo pela presença dos excrementos dos animais no local, o que favoreceu uma reciclagem do $\mathrm{N}$ aplicado na pastagem e na cultura, havendo um melhor aproveitamento dos nutrientes (Thornley e Verberne, 1990; Assmann et al., 2003). 
LANG, C.R. et al., Integração lavoura pecuária ...
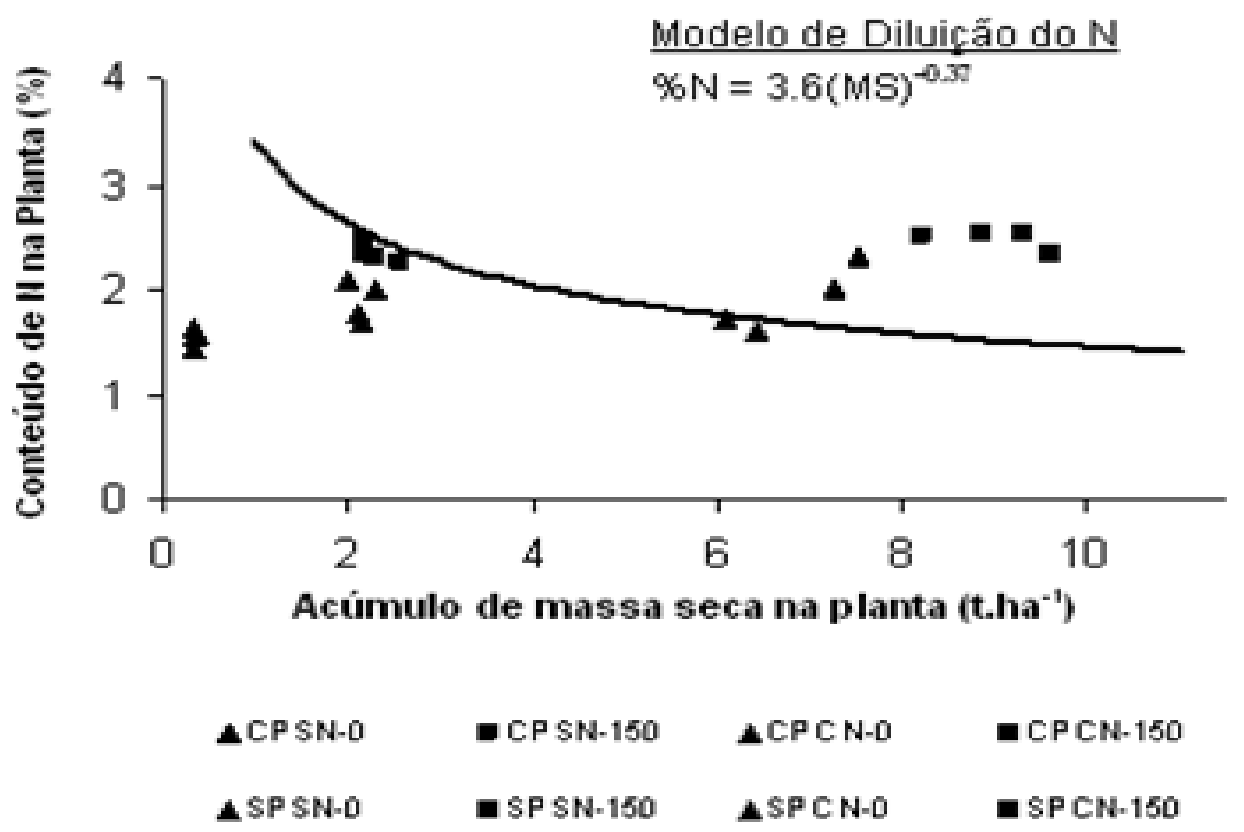

Figura 2. Curva padrão do conteúdo de $\mathrm{N}$ na planta e a massa seca do milho, Ponta Grossa, PR, 2003. (Com pastejo e sem nitrogênio no inverno e no verão - CPSN-0, Com pastejo e sem nitrogênio no inverno e com 150 $\mathrm{kg} \mathrm{ha}^{-1}$ de $\mathrm{N}$ no verão - CPSN-150, Com pastejo e com nitrogênio no inverno e sem nitrogênio no verão $\mathrm{CPCN}-0$, Com pastejo e com nitrogênio no inverno e $150 \mathrm{~kg} \mathrm{ha}^{-1}$ de $\mathrm{N}$ no verão - CPCN-150, SPSN-0, sem pastejo e sem nitrogênio no inverno e sem $\mathrm{N}$ no verão SPSN-150, sem pastejo e sem nitrogênio no inverno e com $150 \mathrm{~kg} \mathrm{ha}^{-1}$ de $\mathrm{N}$ no verão, SPCN-0, sem pastejo e com nitrogênio no inverno e sem N no verão, SPCN150 , sem pastejo e com nitrogênio no inverno e com $150 \mathrm{~kg} \mathrm{ha}^{-1}$ de $\mathrm{N}$ no verão).

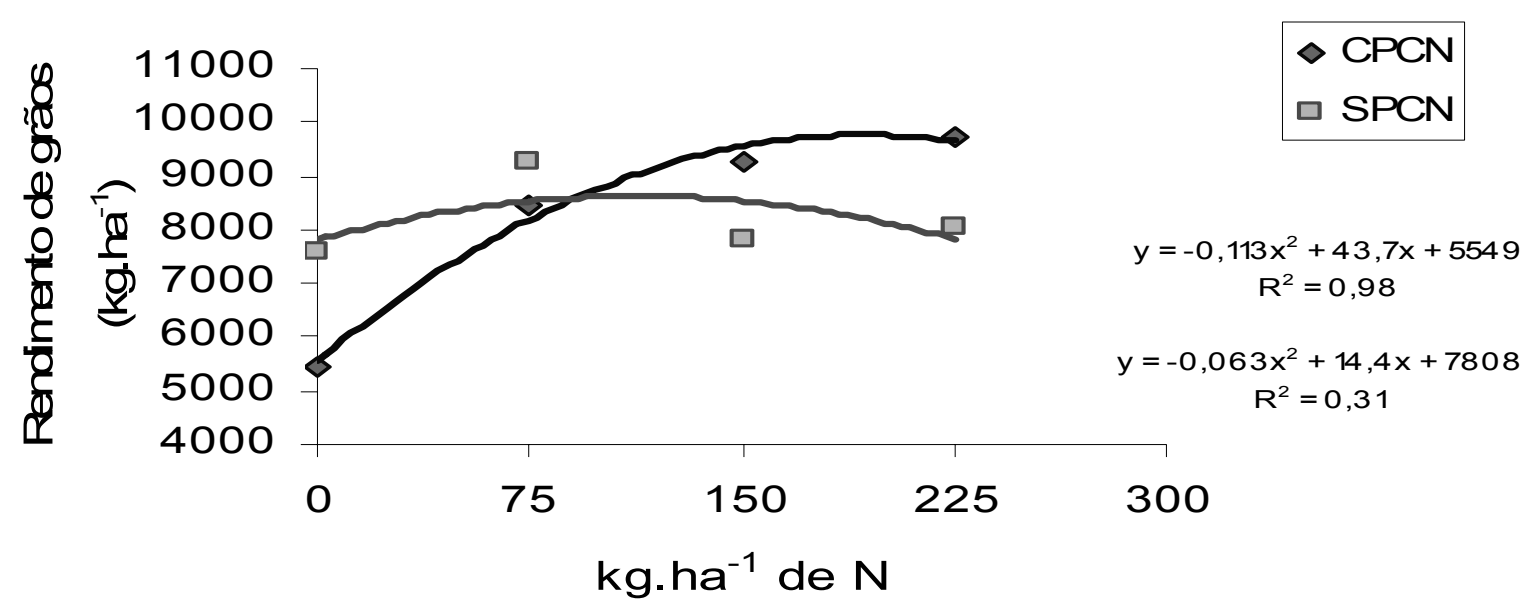

Figura 3. Rendimento em grãos do milho $\left(\mathrm{kg} \mathrm{ha}^{-1}\right)$ na presença e ausência de pastejo sob diferentes doses de nitrogênio na cultura, Ponta Grossa, PR, 2003. (Com pastejo com nitrogênio - CPCN; Sem pastejo com nitrogênio - SPCN). 
LANG, C.R. et al., Integração lavoura pecuária ...

Derpsch e Calegari (1985) ressaltam a importância da utilização da aveia preta pela sua alta capacidade de extração e de acumulação de $\mathrm{N}$ na matéria seca (147 kg ha-1), fazendo com que sua contribuição seja maior para o rendimento do milho, reduzindo o efeito de imobilização pela adição de nitrogênio na dose de $150 \mathrm{~kg} \mathrm{ha}{ }^{-1}$ sobre a pastagem. Logo, as parcelas que foram pastejadas e não receberam adubação nitrogenada apresentaram uma produtividade do milho bastante baixa (2872 $\mathrm{kg} \mathrm{ha}^{-1}$ ) (Tabela 2), mostrando uma influência negativa do animal no sistema quando a pastagem não é adequadamente manejada.

A utilização das diferentes doses de $\mathrm{N}$ na cultura do milho mostrou ser mais eficiente quando aplicada sobre as parcelas SPSN, atingindo 10288 $\mathrm{kg} \mathrm{ha}^{-1}$ para dose de $225 \mathrm{~kg} \mathrm{ha}^{-1}$ de $\mathrm{N}$, porém na parcela SPCN com apenas $75 \mathrm{~kg} \mathrm{ha}^{-1}$ de $\mathrm{N}$ no milho foi possível atingir uma produção de grãos de 9256 $\mathrm{kg} \mathrm{ha}^{-1}$ (Tabela 2), comprovando que o $\mathrm{N}$ aplicado na pastagem permaneceu disponível para a cultura cultivada posteriormente, permitindo reduzir a adubação nitrogenada na cultura. Quando se entra com pastejo, se faz então necessário uma adubação nitrogenada da pastagem para que ocorra um aproveitamento mais eficiente do $\mathrm{N}$ aplicado a cultura posterior. Na Figura 4 se observa a interferência do pastejo em aumentar a resposta do milho à adubação nitrogenada, provavelmente isto se deve ao aumento da dinâmica $e$ biodiversidade de microrganismo do solo, tendendo a um maior equilíbrio do meio.

O efeito do nitrogênio aplicado no inverno sobre a produtividade de milho se mostrou significativo principalmente nas parcelas SPCN (fitomassa de $7214 \mathrm{~kg} \mathrm{ha}^{-1}$ ) a qual sofreu diferimento aos 45 dias, apresentando uma fitomassa superior às demais (5162 kg ha-1), evidenciando a utilização e eficiência do nitrogênio residual em aumentar a produtividade de grãos quando este não foi adubado com nitrogênio.

De acordo com Silva et al. (2006), a necessidade de se fazer uma adubação no milho de pelo menos $30 \mathrm{~kg} \mathrm{ha}^{-1}$ de $\mathrm{N}$ é devido ao processo de imobilização do $\mathrm{N}$ o que pode fazer com que haja falta deste nutriente à cultura do milho no período de maior demanda, concordando com Sá (1993). Segundo Pauletti (1998), a aplicação de N na semeadura da aveia $\left(30 \mathrm{~kg} \mathrm{ha}{ }^{-1}\right)$ não proporcionou aumento significativo na produtividade de grãos de milho, provavelmente este resultado se deve a baixa dose de $\mathrm{N}$ utilizada, o que pode ter levado à uma imobilização deste nutriente. Mai et al. (2003) comprovaram que no plantio direto, quando o milho é cultivado em sucessão à aveia preta (alta relação $\mathrm{C} / \mathrm{N}$ ), os 20 a $30 \mathrm{~kg} \mathrm{ha}^{-1}$ de $\mathrm{N}$ que são recomendados para a cultura por ocasião da semeadura podem ser insuficientes para atender às necessidades das plantas de milho nos estádios iniciais de seu crescimento e desenvolvimento.

\section{CONCLUSÃO}

O milho apresenta uma resposta de produtividade crescente para o aumento das doses de $\mathrm{N}$ nas áreas sem pastejo e sem adubação nitrogenada no inverno, no entanto, nas áreas pastejadas é possível alcançar maiores produtividades de milho com menores doses de nitrogênio.

A aplicação de $150 \mathrm{~kg} \mathrm{ha}^{-1}$ de nitrogênio na aveia-preta + azevém não pastejada permitiu ganhos de produtividade no milho superior a 7000 $\mathrm{kg} \mathrm{ha}^{-1}$, apenas com o nitrogênio residual.

\section{REFERÊNCIAS}

1. AMADO, T.J.C.; MIELNICZUK, J.; AITA, C. Recomendação de adubação nitrogenada para o milho no RS e SC adaptada ao uso de culturas de cobertura do solo, sob sistema de plantio direto. Revista Brasileira de Ciência do Solo, v. 26, p.241-248, 2002.

2. ASSMANN, T.S. et al. Rendimento de milho em área de integração lavoura-pecuária sob o sistema de plantio direto, em presença e ausência de trevo branco, pastejo e nitrogênio. Revista Brasileira de Ciência do Solo, v. 27, p.675683, 2003

3. BAETHGEN, W.E. Dinamica del nitrógeno en sistemas de rotacion cultivos-pasturas. Revista INIA de Investigaciones Agronómicas. Montevideu, v.1, n.1, p.3-25, 1992.

4. BALBINOT JUNIOR, A.A. et al. Integração lavoura-pecuária: intensificação do uso de áreas agrícolas. Ciência Rural Santa Maria. Online: ISSN 0103-8478, 2009.

5. BAYER, C.; MIELNICZUCK, J. Características químicas do solo afetadas por métodos de preparo e sistemas de cultura. Revista Brasileira de Ciência do Solo, Campinas, v.21, p.105-112, 1997.

6. CANTARELLA, H.; DUARTE, A.P. Manejo da fertilidade do solo para a cultura do milho. In: GALVÃO, J.C.C. MIRANDA, G.V., eds. Tecnologia de produção de milho. Viçosa, MG, Universidade Federal de Viçosa, 2004. p.139-182.

7. DERPSCH, R.; CALEGARI, A. Guia de plantas para adubação verde de inverno. Londrina, IAPAR, 1985. 96p. (Documento IAPAR 9).

8. EMBRAPA- EMPRESA BRASILEIRA DE PESQUISA AGROPECUÁRIA. Manual de análises químicas de solos, plantas e fertilizantes. Brasília: EMBRAPA, 1999. 370p.

9. FERNANDES, F.C.S. et al. Doses, eficiência e uso de nitrogênio por seis cultivares de milho. Revista Brasileira de Milho e Sorgo, v.4, n.2, p.195-204, 2005.

10. GERAGE, A.C.A Cultura do Milho no Paraná. In: Milho-Estratégias de Manejo Para a Região Sul, 2000, p.209.

11. IAPAR - Instituto Agronômico do Paraná. Cartas Climáticas do Estado do Paraná, 1984. Londrina: IAPAR, 1994. 49p.

12. JONES JR, J.B.; WOLF, B.; MILLS, H.A. Plant analysis handbook: a practical sampling, preparation, analysis, and interpretation guide. Athens: Micro-Macro, 1991. 213p. 
LANG, C.R. et al., Integração lavoura pecuária ...

13. LEMAIRE, G.; GASTAL, F. N uptake and distribution in plant canopies. In: Diagnosis of the nitrogen status in crops. G. LEMAIRE (Ed.) Springer-Verlag Berlin Heidelberg. 1997. Cap. 1, p. 3-43.

14. LUO, J.; TILLMAN, R.W.; BALL, P.R. Nitrogen loss trough denitrification in a soil under pasture in New Zwealand. Soil Biology \& Biochemistry, v. 32, p. 497-509, 2000.

15. PAULETTI, V. Nutrientes: Teores e interpretações. Campinas: Fundação Cargill, 1998. p. 59.

16. MAI, M.E.M.; CERETTA, C.A.; BASSO, C.J.; SILVEIRA, M.J.; PAVINATO, A.; PAVINATO, P.S. Manejo da adubação nitrogenada na sucessão aveia-preta/milho no sistema plantio direto. Pesquisa Agropecuária Brasileira, v.38, p.125-131, 2003.

17. MELLO, F. A. de; SOBRINHO, M. D. C. de ARZOLLA, S. SILVEIRA, R. I., NETTO, A. C.; KIEHL, J. C. de. Fertilidade do solo. São Paulo: Nobel, 1989.

18. SÁ, J.C. de M. Manejo da fertilidade do Solo no Plantio Direto, Castro: Fundação ABC, p. 96,1993.

19. SILVA, E.C.; MURAOKA, T.; BUZETTI, S. \& TRIVELIN, P.C.O. Manejo de nitrogênio no milho sob plantio direto com diferentes plantas de cobertura, em Latossolo Vermelho. Pesquisa Agropecuária Brasileira. 41:477-486, 2006.

20. SINGH, R. S.; RAGHUBANSHI, A.S. e SINGH, J. S. Nitrogen mineralization in dry tropical savanna: Effects of burning and grazing. Soil Biology and Biochemistry, v.22, p.835-838, 1991.

21. SPERA, S.T. et al. Integração lavoura e pecuária e os atributos físicos de solo manejado sob sistema de plantio direto. Revista Brasileira de Ciência do Solo, v. 33, p.129-136, 2009.

22. TAIZ, L.; ZEIGER, E. Fisiologia Vegetal. 4 ed. Artmed, Porto Alegre, 820p., 2009.

23. THORNLEY, J.H.M.; VERBENE, E.L.J. A model of nitrogen flows in grassland. Plant, Cell and Environment, v. 12 p.863-886, 1990.

24. WATKIN, B.R.; CLEMENTS, R. J. The effects of grazing animals on pasture. In: WILSON, J.R.(ed.) Plants relations in pastures. Melbourne Csiro, 1978, p.273-289.

25. ZONTA, E. P.; MACHADO, A. A. SANEST: sistema de análises estatísticas para microcomputadores. Pelotas-UFPel, 1984. $75 \mathrm{p}$

Recebido em 25/05/2011

Aceito em 29/08/2011 